\title{
Models to predict both sensible and latent heat transfer in the respiratory tract of Morada Nova sheep under semiarid tropical environment
}

\author{
Vinícius Carvalho Fonseca ${ }^{1}$ Edilson Paes Saraiva ${ }^{1}$ - Alex Sandro Campos Maia ${ }^{2}$. \\ Carolina Cardoso Nagib Nascimento ${ }^{2}$. Josinaldo Araújo da Silva ${ }^{1}$. \\ Walter Esfraim Pereira ${ }^{1}$ - Edgard Cavalcanti Pimenta Filho ${ }^{1}$. \\ Maria Elivânia Vieira Almeida ${ }^{1}$
}

Received: 11 January 2016 /Revised: 6 September 2016 / Accepted: 22 September 2016 /Published online: 10 October 2016 (C) ISB 2016

\begin{abstract}
The aim of this study was to build a prediction model both sensible and latent heat transfer by respiratory tract for Morada Nova sheep under field conditions in a semiarid tropical environment, using easily measured physiological and environmental parameters. Twelve dry Morada Nova ewes with an average of $3 \pm 1.2$ years old and average body weight of $32.76 \pm 3.72 \mathrm{~kg}$ were used in a Latin square design $12 \times 12$ (12 days of records and 12 schedules). Tidal volume, respiratory rate, expired air temperature, and partial vapor pressure of the expired air were obtained from the respiratory facial mask and using a physiological measurement system. Ewes were evaluated from 0700 to $1900 \mathrm{~h}$ in each day under shade. A simple nonlinear model to estimate tidal volume as a function of respiratory rate was developed. Equation to estimate the expired air temperature was built, and the ambient air temperature was the best predictor together with relative humidity and ambient vapor pressure. In naturalized Morada Nova sheep, respiratory convection seems to be a mechanism of heat transfer of minor importance even under mild air temperature. Evaporation from the respiratory system increased together with ambient air temperature. At ambient air temperature, up to $35{ }^{\circ} \mathrm{C}$ respiratory evaporation accounted $90 \%$ of the total heat lost by respiratory system, on average. Models presented
\end{abstract}

Electronic supplementary material The online version of this article (doi:10.1007/s00484-016-1255-3) contains supplementary material, which is available to authorized users.

Vinícius Carvalho Fonseca

vinicius_fonseca86@hotmail.com

1 Universidade Federal da Paraiba, Paraiba, Areia, Brazil

2 Universidade Estadual Paulista, São Paulo, Jaboticabal, Brazil here allow to estimate the heat flow from the respiratory tract for Morada Nova sheep bred in tropical region, using easily measured physiological and environmental traits as respiratory rate, ambient air temperature, and relative humidity.

Keywords Genetic adaptation · Naturalized breed · Prediction model $\cdot$ Tidal volume

\section{Introduction}

Mathematical models have been developed to evaluate heat exchange at the respiratory surfaces in cattle and sheep (Stevens 1981; da Silva et al., 2002; Berman, 2005; Maia et al., 2005). These models were conceived using easily measured environmental and physiological parameters to estimate heat dissipation through the respiratory tract via convection and evaporation under field conditions. Models of evaporation in the respiratory system of animals generally assume that expired air is saturated at a temperature lower than deep body temperature, evincing that environmental air temperature, humidity, and body temperature are important factors for the determination of evaporation in the respiratory tract (Stevens 1981; da Silva et al., 2002; Maia et al., 2005).

Equations to estimate heat loss via the respiratory tract should take factors like species, breed, and environment which they were selected. Maia et al. (2005) showed that using functions estimated from animals bred in temperate climates were inappropriate for animals bred under tropical conditions. They studied Holstein cows acclimatized to a tropical environment and observed that measures like tidal volume were underestimated when they used equations developed by Stevens (1981) for Holstein cows bred in a temperate zone. 
In the case of sheep, da Silva et al. (2002) developed functions with Corriedale sheep, but these are evolutionarily distinct from breeds naturalized to the semiarid tropical environment. Morada Nova sheep are known to be well adapted to the semiarid environment of Brazil (Egito et al., 2002; Fonsêca et al., 2014). By contrast, Corriedale sheep were selected for temperate climates and are characterized by a wool coat.

Studies have shown that evaporation in the respiratory tract is the main avenue of heat dissipation at high ambient temperatures in wool sheep (Alexander and Williams, 1962; Hofmeyr et al., 1969; Hofman and Riegle, 1977). Starling et al. (2002) showed that at high ambient temperature, respiratory heat transfer accounted for approximately $70 \%$ of total heat loss in Corriedale bred in a tropical zone. On the other hand, in a study of naturalized goats from a semiarid tropical zone, Maia et al. (2015) documented that evaporative heat loss by the respiratory tract was only $7 \%$ of total heat loss under conditions of high temperature.

In sum, specific physiological responses in animals are related to the environment that they are adapted to. Therefore, mathematical models of heat transfer should take this into account. No attempt has been made to evaluate the characteristics of the respiratory system in heat exchange in naturalized sheep bred in a semiarid tropical environment. Thus, the aim of this study was to build predictive models of both sensible and latent heat transfer in the respiratory tract of Morada Nova sheep under field conditions in a semiarid tropical environment, using easily measured physiological and environmental traits.

\section{Materials and methods}

Twelve dry Morada Nova, Ovis aries, ewes averaging $3 \pm 1.2$ years in age and $32.76 \pm 3.72 \mathrm{~kg}$ in body weight were studied in a $12 \times 12$ Latin square design (12 days of records and 12 schedules). Observations were made from April to May 2015. Ewes were evaluated under ambient conditions in São João do Cariri, PB, Brazil $\left(07^{\circ} 23^{\prime} 27^{\prime \prime} \mathrm{S}, 36^{\circ} 31^{\prime} 58^{\prime \prime}\right.$ $\mathrm{W}, 458 \mathrm{~m}$ altitude), from 0700 to $1900 \mathrm{~h}$ each day under shade. Physiological parameters were recorded in the first animal between 0700 and $0800 \mathrm{~h}$, the second between 0800 and $0900 \mathrm{~h}$, and so on. Thus, the twelfth animal was evaluated between 1800 and $1900 \mathrm{~h}$. By the end of the trial, every animal had been evaluated on each of the 12 days in all the schedules. Ewes were fed twice a day (0530 and $1910 \mathrm{~h}$ ) with forage (elephant grass hay) and concentrate (corn, soybean, wheat, and mineral supplementation) in a ratio of 74:26. Water was provided ad libitum. Daily feed consumption was estimated at approximately $1.5 \%$ of average body weight.

Sensible and latent heat flows from the respiratory tract were determined according to the methods described by
Maia et al. (2005) and da Silva and Maia (2013). The sensible heat flow $\left(\mathrm{C}_{\mathrm{R}} ; \mathrm{W} \mathrm{m}^{-2}\right)$ from the respiratory system is given by

$\mathrm{C}_{\mathrm{R}}=\mathrm{A}^{-1} \mathrm{~V}_{\mathrm{T}} p c_{P} F\left(\mathrm{~T}_{\mathrm{E}}-\mathrm{Tar}\right)$

and the latent heat flow $\left(\mathrm{E}_{\mathrm{R}} ; \mathrm{W} \mathrm{m}^{-2}\right)$ by

$\mathrm{E}_{\mathrm{R}}=\mathrm{A}^{-1} \lambda \mathrm{V}_{\mathrm{T}} F\left(\psi_{\mathrm{E}}-\psi_{\mathrm{atm}}\right)$

where Tar and $\mathrm{T}_{\mathrm{E}}$ are the temperatures of the ambient and expired air $\left({ }^{\circ} \mathrm{K}\right)$, respectively; $p$ is the air density $\left(\mathrm{kg} \mathrm{m}^{-3}\right), \mathrm{c}_{\mathrm{P}}$ is the specific heat of the air $\left(\mathrm{J} \mathrm{kg}^{-1}{ }^{\circ} \mathrm{C}^{-1}\right), \lambda$ is the latent heat of water vaporization $\left(\mathrm{J} \mathrm{g}^{-1}\right), \mathrm{V}_{\mathrm{T}}$ is the tidal volume $\left(\mathrm{L} \mathrm{breaths}^{-1}\right)$, $F$ is the respiratory rate (breaths $\mathrm{s}^{-1}$ ), and $\mathrm{A}$ is the body surface area of the animal, which is estimated as (Bennett, 1973):

$\mathrm{A}=0.171 \mathrm{~B}_{\mathrm{W}}{ }^{-0.05025}$

where, $\mathrm{B}_{\mathrm{W}}$ is body weight of the animal $(\mathrm{Kg})$. The absolute humidity of the ambient air $\left(\psi_{\mathrm{atm}} ; \mathrm{g} \mathrm{m}^{-3}\right)$ and of the expired air $\left(\psi_{\mathrm{E}} ; \mathrm{g} \mathrm{m}^{-3}\right)$ are given by

$\psi_{\mathrm{atm}}=\operatorname{Tar}^{-1} 2166.87 e(\operatorname{Tar})$

$\psi_{\mathrm{E}}=\mathrm{T}_{\mathrm{E}}^{-1} 2166.87 e\left(\mathrm{~T}_{\mathrm{E}}\right)$

which $e(\mathrm{Tar})$ and $e\left(\mathrm{~T}_{\mathrm{E}}\right)$ are the partial vapor pressures $(\mathrm{kPa})$ of the ambient and expired air, respectively. Thermal properties of the air $\left(p, \lambda\right.$, and $\left.c_{\mathrm{P}}\right)$ were obtained from a simple function of Tar (Da Silva, 2008).

The respiratory parameters tidal volume $\left(\mathrm{L} \mathrm{breaths}^{-1}\right)$, respiratory rate, expired air temperature $\left({ }^{\circ} \mathrm{C}\right)$, and partial vapor pressure of the expired air $(\mathrm{kPa})$ were obtained using a respiratory facial mask and a physiological measurement system (Maia et al., 2016). Ambient air temperature $\left({ }^{\circ} \mathrm{C}\right.$; model $\mathrm{HOBO}$, onset), relative humidity (\%; model HOBO, onset), partial vapor pressure of the air $(\mathrm{kPa})$, rectal temperature $\left({ }^{\circ} \mathrm{C}\right)$, and wind speed ( $\mathrm{m} \mathrm{s}^{-1}$; model APM-360, USA) were also collected. In addition, black globe temperature $\left({ }^{\circ} \mathrm{C}\right)$ was measured with a thermocouple (Model type T, Salcas, Brazil. Accuracy $0.2{ }^{\circ} \mathrm{C}$ ) inserted into the centre of a hollow 0.15$\mathrm{m}$-diameter copper sphere, matt black painted, which was placed $50 \mathrm{~cm}$ above the ground near the animals. The mean radiant temperature (K) was obtained according to da Silva et al. (2010). Prior to the study, the ewes were habituated and conditioned to the use of the respiratory mask using operant conditioning principles employing feed as a positive reinforcement. This habituation period extended from December 2014 to March 2015. 
During each breath, the inlet flow (inspired air) and the outlet flow (expired air) were carried through two valves of the measurement system (Fig. 1). The expired air leaving the facial mask was directed through a tracheal tube (MLA1015 Breathing Tube, ADInstruments, Australia) to a flow head (MLT1.000, ADInstruments, Australia). The flow head was directed to a gas mixing-chamber (MLA246, ADInstruments, Australia) connected to a spirometer (ML141, ADInstruments, Australia) providing the ventilation $\left(\mathrm{V}_{\mathrm{R}}\right.$; $\mathrm{L} \mathrm{s}^{-1}$ ) and respiratory rates $\left(\mathrm{min}^{-1}\right)$. From these measurements, we calculated the tidal volume $\left(\mathrm{V}_{\mathrm{T}} ; \mathrm{L}_{\text {breaths }}{ }^{-1}\right)$. The gas-mixing chamber was connected to a Field Metabolic System (FMS-1201-05, Sable System, USA) through a plastic tube (Bevaline Tubing, Sable System, USA). Inside the tube, a sample of expired air $(150 \mathrm{~mL} / \mathrm{min})$ was continuously pumped into a gas analyzer $\left(\mathrm{H}_{2} \mathrm{O}\right)$ to measure the partial vapor pressure of the expired air $(\mathrm{kPa})$. These measurements were performed every time a facial mask was placed on an animal's muzzle.

Atmospheric vapor pressure was continuously recorded by an external $\mathrm{H}_{2} \mathrm{O}$ vapor analyzer $\left(\mathrm{P}_{\mathrm{v}}, \mathrm{kPa}\right.$; $\mathrm{RH}-300$, Sable System, USA) connected to a pump (SS4, Sable System, USA), which continuously aspirated atmospheric air $\left(150 \mathrm{ml} \mathrm{min}^{-1}\right)$ close to the mask's inlet valve. The expired air temperature was recorded with a nasal temperature probe (MLT 415/AL, ADInstruments, Australia, accuracy $\pm 0.3{ }^{\circ} \mathrm{C}$ ) placed inside the facial mask. The rectal temperature $\left({ }^{\circ} \mathrm{C}\right)$ was continuously recorded with a rectal thermocouple (MLT 1404, ADInstruments, Australia, accuracy $\pm 0.3{ }^{\circ} \mathrm{C}$ ). The FMS, spirometer, $\mathrm{H}_{2} \mathrm{O}$ vapor analyzer, and thermocouples were connected to a data acquisition system (PowerLab 16/32, ADInstruments, Australia) and linked to a computer that continuously and simultaneously recorded all measurements at a rate of one observation per second.

Data were analyzed using general linear models and least squares methods. Nonlinear regression was used to estimate $\mathrm{V}_{\mathrm{T}}$ as a function of the respiratory rate. Multiple regression was used to develop a model for $F, \mathrm{~T}_{\mathrm{E}}, \mathrm{C}_{\mathrm{R}}$, and $\mathrm{E}_{\mathrm{R}}$, as a function of several variables, given the initial model:

$$
\begin{aligned}
\mathrm{y}_{\mathrm{ijkl}}= & \alpha+\mathrm{a}_{\mathrm{i}}+\mathrm{t}_{\mathrm{j}}+\mathrm{d}_{\mathrm{k}}+\mathrm{b}_{1}(\text { Tar })+\mathrm{b}_{2}\left(\mathrm{R}_{\mathrm{H}}\right)+\mathrm{b}_{3} e(\text { Tar }) \\
& +\mathrm{b}_{4}\left(\mathrm{~T}_{\mathrm{B}}\right)+\varepsilon_{\mathrm{ijkl}}
\end{aligned}
$$

where $y_{i j k l}$ is the $1^{\text {th }}$ observation of $T_{E}, F, C_{R}$, and $E_{R}$ in the $i^{\text {th }}$ animal, $\mathrm{j}^{\text {th }}$ time of the day and $\mathrm{k}^{\text {th }}$ day of records, $\alpha$ is the intercept, $a_{i}$ is the effect of the $i^{\text {th }}$ animal $(i=1, \ldots, 12), t_{j}$ is the effect of $j^{\text {th }}$ time of the day $(k=0700, \ldots, 1800 \mathrm{~h})$, and $d_{k}$ is the effect of the $\mathrm{k}^{\text {th }}$ day of records $(\mathrm{k}=1, \ldots, 12)$. The values of $b_{1}, b_{2}, b_{3}$, and $b_{4}$ are partial linear regression coefficients and $\varepsilon_{\mathrm{ijkl}}$ is the random error associated with the $1^{\text {th }}$ observation on the $\mathrm{i}^{\text {th }}$ animal, $\mathrm{j}^{\text {th }}$ time of the day, and $\mathrm{k}^{\text {th }}$ day of record. Starting with Tar, independent variables were successively added to the model until the largest coefficient of determination $\left(R^{2}\right)$ was reached. At each step, a set of simultaneous equations was built and then solved by stepwise selection. The statistical package used for all analyses was SAS version 9.3 (SAS Inst. Inc., Cary, NC).

\section{Results and discussion}

From the data obtained in our study, we estimated the relationship between tidal volume and respiratory rate for woolless Morada Nova sheep bred in semiarid environment $\left(R^{2}=0.95\right.$; Fig. 2$)$ as

$$
\mathrm{V}_{\mathrm{T}}\left(\mathrm{L} \text { breath }^{-1}\right)=10.0351 F^{-1.0376}
$$

$\mathrm{V}_{\mathrm{T}}$ ranged from 0.345 to $0.644 \mathrm{~L} /$ breath under ambient conditions of air temperature $\left(25.07\right.$ to $\left.35.56{ }^{\circ} \mathrm{C}\right)$, radiant mean temperature $\left(25.22\right.$ to $\left.46.39{ }^{\circ} \mathrm{C}\right)$, relative humidity (35.84\% to $78.47 \%$ ), and vapor pressure (1.42 to $2.82 \mathrm{kPa}$; Table 1). Previous findings of sheep described similar
Fig. 1 Physiological measurement system using facial mask developed for sheep

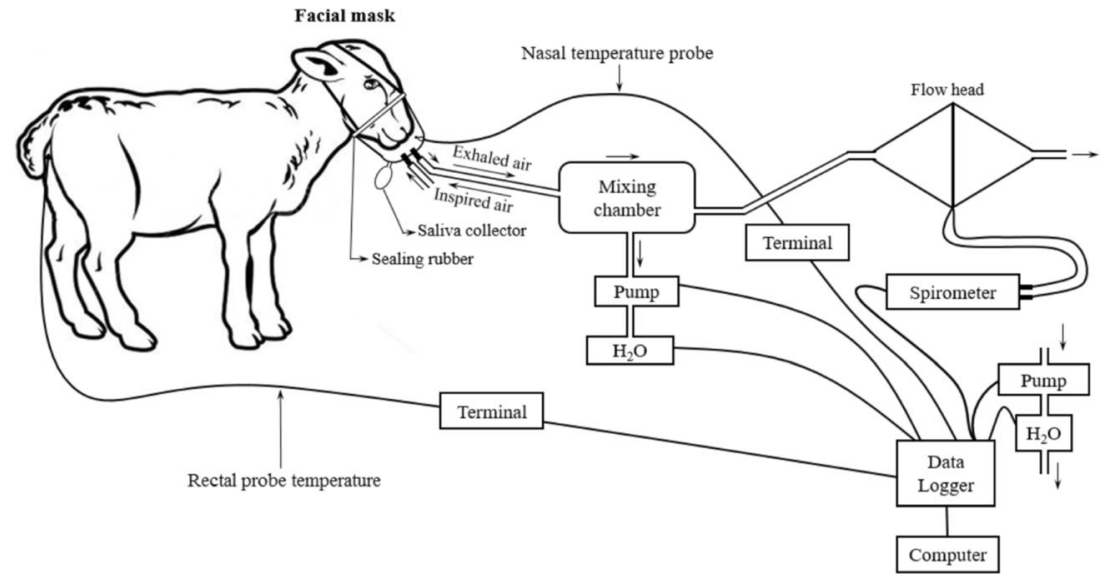


Fig. 2 Tidal volume as a function of the respiration rate

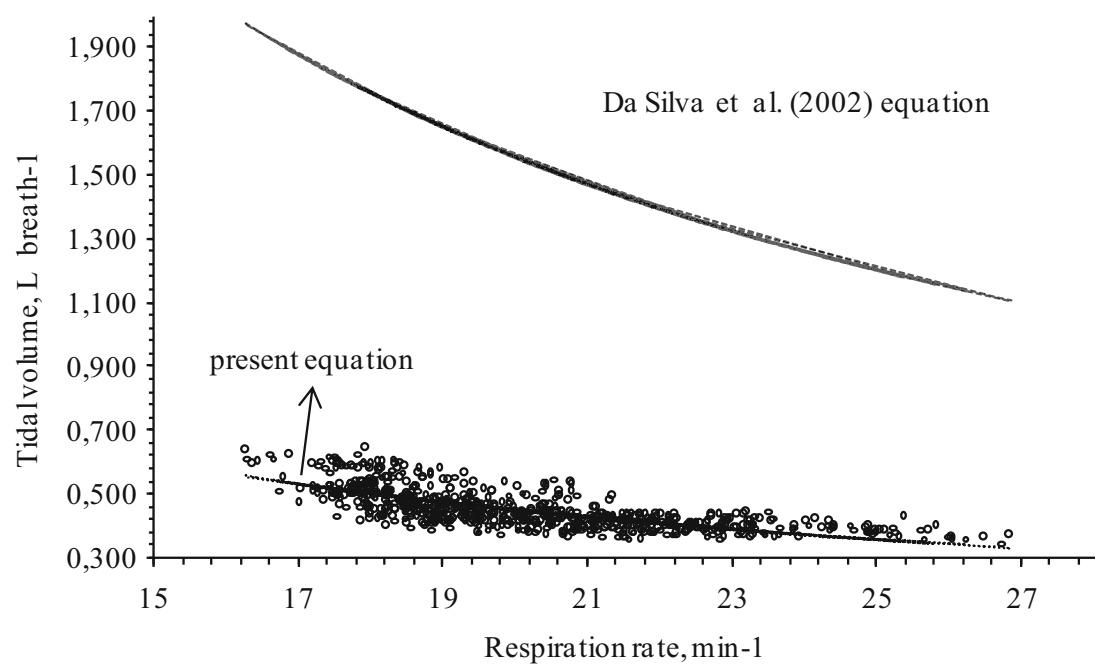

variation for tidal volume on resting conditions (Mitchell 1972; Hofman and Riegle 1977; Schmitd-Nielsen 1991; da Silva et al. 2002). For example, Schmidt-Nielsen (1991) measured a tidal volume of $0.403 \mathrm{~L} / \mathrm{breath}$ for a $60-\mathrm{kg}$ sheep. Da Silva et al. (2002), working with Corriedale ewes under ambient temperatures ranging from 17.5 to $40{ }^{\circ} \mathrm{C}$, documented tidal volumes from 0.200 to $0.700 \mathrm{~L} /$ breath. Similarly, shorn and unshorn Dorset ewes presented tidal volumes from 0.150 to $0.400 \mathrm{~L} /$ breath (Hofman and Riegle, 1977).

According to this model, an increase in $F$ (breaths $\mathrm{min}^{-1}$ ) decreased the $\mathrm{V}_{\mathrm{T}}$, consistent with other studies of sheep (Hofman and Riegle, 1977; da Silva et al. 2002; Silva, 2013) and cattle (Stevens, 1981; Maia et al., 2005). Variation in the respiratory rate as a function of ambient air temperature was described by the equation $\left(R^{2}=0.61\right)$ :

$F=49.86-2.472 \mathrm{Tar}+0.047 \operatorname{Tar}^{2}$,

$F$ ranged from 16.26 to 26.83 (Fig. 3). When other variables such as ambient vapor pressure, relative humidity, and rectal temperature were included in the model, $R^{2}$ did not increase. In the present study, the range of ambient and mean

Table 1 Average, minimum, and maximum values of air temperature (Tar), relative humidity $\left(\mathrm{R}_{\mathrm{H}}\right)$, mean radiant temperature $\left(\mathrm{T}_{\mathrm{RM}}\right)$, wind speed $\left(\mathrm{W}_{\mathrm{S}}\right)$, and ambient vapor pressure $(e[\mathrm{Tar}])$ observed in São João do Cariri from April to May, 2015

\begin{tabular}{lllll}
\hline Variable & $n$ & Average & Minimum & Maximum \\
\hline Tar, ${ }^{\circ} \mathrm{C}$ & 748 & $31.84 \pm 0.27$ & 25.07 & 37.02 \\
$\mathrm{R}_{\mathrm{H}}, \%$ & 743 & $49.04 \pm 1.24$ & 25.22 & 42.39 \\
$\mathrm{~T}_{\mathrm{RM}}{ }^{\circ} \mathrm{C}$ & 702 & $32.40 \pm 0.30$ & 35.84 & 78.47 \\
$\mathrm{~W}_{\mathrm{S},} \mathrm{m} \mathrm{s}^{-1}$ & 452 & $0.32 \pm 0.04$ & 0 & 1.21 \\
$e($ Tar), $\mathrm{kPa}$ & 740 & $1.94 \pm 0.05$ & 1.42 & 2.82 \\
\hline
\end{tabular}

radiant temperature was not sufficient to cause panting in the ewes. Working with wool-less Santa Inês sheep bred in a tropical environment, Neiva et al. (2004) documented close range for $F$ under both shady and sunny conditions. However, large variation in $F$ under a similar range of ambient temperature was observed in wool sheep under panting state (Hofman and Reagle, 1977; Johnson, 1991; da Silva and Starling, 2003; Silva, 2013). With Merino ewes, Johnson (1991) described variation in the respiration rate from 65 to 120 breaths per minute. Similarly, Silva (2013) observed respiratory rates of 155 to 180 breaths per minute in male Corriedale maintained in a climatic chamber (average ambient temperature of $30^{\circ} \mathrm{C}$ ).

When we plotted the data of the present study using the nonlinear function of da Silva et al. $\left(2002 ; \mathrm{V}_{\mathrm{T}}\left(\mathrm{m}^{3}\right)\right.$ breath) $=0.0496 F^{-0.463}$ ), the curve deviated from the data, showing a large overestimate for the tidal volume (Fig. 2). Maia et al. (2005) worked with Holstein cows acclimatized to a hot environment and observed that when they used a function estimated by Stevens (1981) for Holstein cows bred in a temperate climate, the estimates

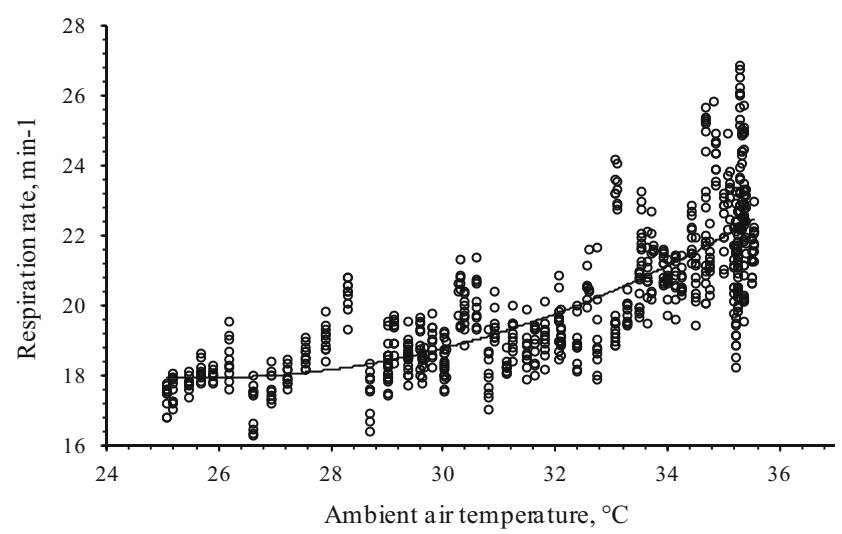

Fig. 3 Respiration rate as a function of ambient air temperature 
Table 2 Correlation coefficients among ambient air temperature (Tar), partial air vapor pressure (Pvatm), rectal temperature $\left(T_{R}\right)$, relative humidity $\left(\mathrm{R}_{\mathrm{H}}\right)$, and expired air temperature $\left(\mathrm{T}_{\mathrm{E}}\right)$

\begin{tabular}{ccccccc}
\hline Variable & Tar & $e($ Tar $)$ & $\mathrm{T}_{\mathrm{R}}$ & $\mathrm{R}_{\mathrm{H}}$ & $\mathrm{T}_{\mathrm{E}}$ & $P$ value \\
\hline $\mathrm{Tar}$ & 1 & -0.8270 & 0.3485 & -0.9442 & 0.9588 & 0.001 \\
$e($ Tar $)$ & - & 1 & -0.3854 & 0.9491 & -0.7799 & 0.001 \\
$\mathrm{~T}_{\mathrm{R}}$ & - & - & 1 & -0.3820 & 0.4083 & 0.001 \\
$\mathrm{R}_{\mathrm{H}}$ & - & - & - & 1 & -0.8917 & 0.001 \\
$\mathrm{~T}_{\mathrm{E}}$ & - & - & - & - & 1 & 0.001 \\
\hline
\end{tabular}

deviated from the data, underestimating tidal volume. A similar pattern was found by Silva and Maia (2011) using a function provided by Gatenby (1986) to estimate cutaneous evaporation in cattle as a function of surface temperature. These authors worked with Holstein cows in a tropical environment while Gatenby (1986) developed the equation for crossbred beef cattle.

Correlation coefficients of $\mathrm{T}_{\mathrm{E}}$ with respect to ambient air temperature (Tar), ambient vapor pressure $e(T a r)$, rectal temperature $\left(T_{R}\right)$, and relative humidity $\left(R_{H}\right)$ are shown in Table 2. $T_{E}$ is more a function of the ambient air temperature, relative humidity, and ambient vapor pressure than rectal temperature (Fig. 4a-d). Based on these relationships, we chose two models that estimate $T_{E}$ with good accuracy. The first $\left(R^{2}=0.9778\right)$ included Tar and $\mathrm{R}_{\mathrm{H}}$ and the second $\left(R^{2}=0.9764\right)$ included Tar and $e$ (Tar). The inclusion of $e$ (Tar) in the first function and $\mathrm{R}_{\mathrm{H}}$ in the second did not increase the $R^{2}$. When we included $\mathrm{T}_{\mathrm{R}}$ in both equations, the estimate did not improve. Thus, the models are the following:

$$
\begin{aligned}
& \mathrm{T}_{\mathrm{E}}\left(\begin{array}{c}
\AA \\
1
\end{array}\right)=14.56+0.64 \text { Tar-0.08R } \mathrm{R}_{\mathrm{H}}+0.0007 \mathrm{R}_{\mathrm{H}}^{2}, \\
& \mathrm{~T}_{\mathrm{E}}\left(\begin{array}{c}
\AA \\
2
\end{array}\right)=12.31+0.65 \text { Tar }-0.16 e(\text { Tar }) .
\end{aligned}
$$

However, in both models, the inclusion of only ambient air temperature gave an $R^{2}$ of 0.96 . Thus, the equation presented in Fig. 4a accurately predicted $\mathrm{T}_{\mathrm{E}}$ as a function of Tar. Da Silva et al. (2002) described that the best model $\left(R^{2}=0.96\right)$ of $\mathrm{T}_{\mathrm{E}}$ for Corriedale sheep included Tar, $\mathrm{R}_{\mathrm{H}}$, and deep body temperature $\left(T_{R}\right)$. Stevens (1981) reported that the best model of $T_{E}$ included ambient air temperature and relative humidity. Meanwhile, Maia et al. (2005) reported the best model of $\mathrm{T}_{\mathrm{E}}$ was a function of $\operatorname{Tar}\left(R^{2}=0.91\right)$.

Deep body temperature $\left(T_{R}\right)$ ranged from 38 to 39.18 . The minimum and maximum values were observed at 0700 and 1800 h, respectively. Da Silva and Minomo (1995) reported a similar pattern for Corriedale sheep bred in a tropical environment. According to our investigation, the amount of body thermal energy did not coincide with the highest values of expired air temperature or respiratory rate, which may be an indication that the great part of heat was dissipated in other ways (Fig. 5).
Fig. 4 Expired air temperature as a function of ambient air temperature (a), relative humidity (b), ambient air vapor pressure (c), and rectal temperature (d)
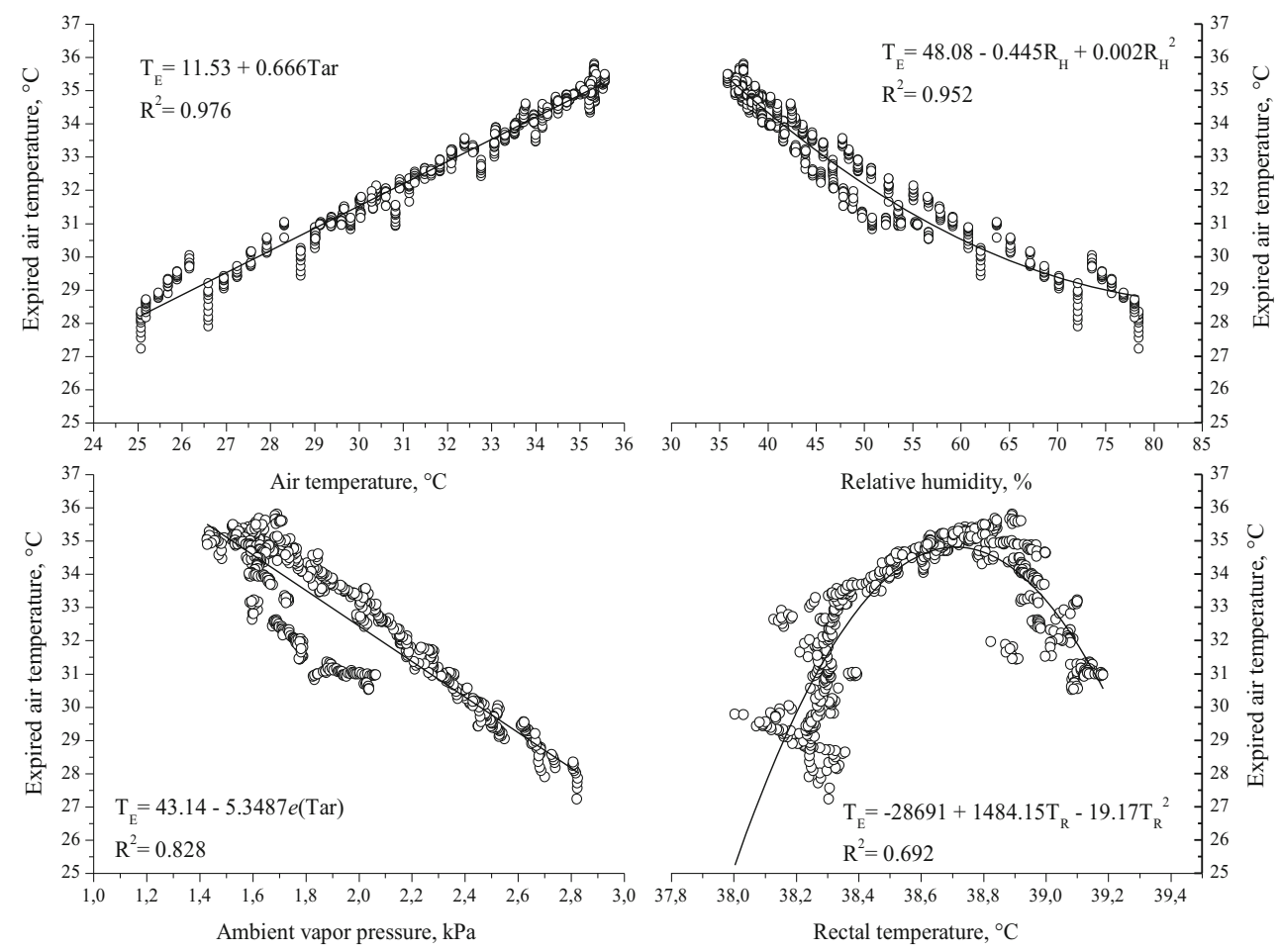
As previously reported in sheep and cattle (Da Silva et al., 2002; Maia et al., 2005), the sensible ( $\mathrm{W} \mathrm{m}^{-2}$ ) heat loss decreased with increasing ambient temperature, while evaporative heat loss increased together with Tar (Fig. 6):

$$
\begin{aligned}
\mathrm{C}_{\mathrm{R}}= & 33.61-2.995 \mathrm{Tar} \\
& +0.092 \mathrm{Tar}^{2}-0.001 \mathrm{Tar}^{3},\left(R^{2}=0.76\right)
\end{aligned}
$$

$$
\begin{aligned}
& \mathrm{E}_{\mathrm{R}}=-295.8+28.49 \mathrm{Tar}-0.909 \mathrm{Tar}^{2} \\
& +0.009 \operatorname{Tar}^{3}\left(R^{2}=0.90\right) \text {. }
\end{aligned}
$$

Sensible heat loss by the respiratory tract in Morada Nova sheep seems to be of little significance for thermal balance, even under mild air temperatures $\left(25^{\circ} \mathrm{C}\right)$. In a similar situation, da Silva et al. (2002) reported values of respiratory convection in Corriedale sheep that ranged 7 to $9 \mathrm{~W} \mathrm{~m}^{-2}$ when the thermal gradient $(\Delta t)$ between ambient and expired air temperature reached $7{ }^{\circ} \mathrm{C}$. In the present study, at $25{ }^{\circ} \mathrm{C}$, the thermal gradient reached 2 or $3{ }^{\circ} \mathrm{C}$, on average. Our study shows that latent heat loss is the main mechanism of respiratory heat loss. At ambient temperatures above $35^{\circ} \mathrm{C}$, respiratory cooling via evaporation accounted for $90 \%$ of total heat lost. As expected, the amount of latent heat lost in Morada Nova sheep is small when compared with the findings of da

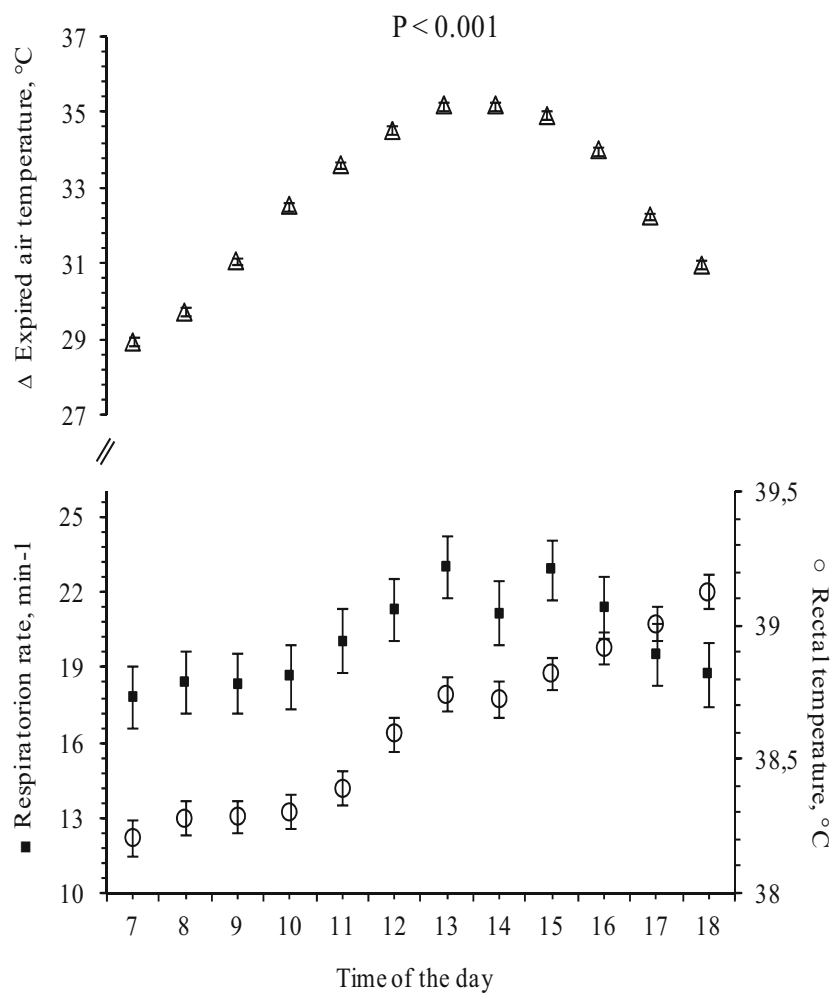

Fig. 5 Respiration rate, rectal temperature, and expired air temperature (mean \pm SEM) during daylight

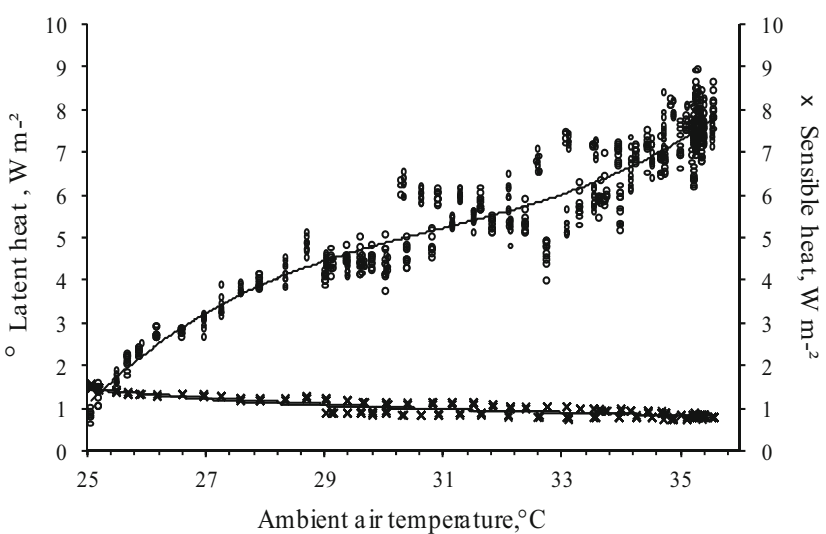

Fig. 6 Heat loss from the convection and evaporation in the respiratory tract of Morada Nova sheep as a function of ambient air temperature

Silva et al. (2002). There is large differences between Morada Nova (weight $=33 \mathrm{~kg}$ on average) and Corriedale (weight $=75 \mathrm{~kg}$ on average) regarding thermal energy content. In other words, heavier animals have a greater capacity for heat storage than lighter animals.

It is evident that there are large differences between woolly and wool-less naturalized sheep bred in a semiarid tropical environment in terms of heat transfer by the respiratory tract. Maia et al. (2005) and Silva and Maia (2011) had already emphasized that the use of the same models for animals bred under tropical and temperate conditions was inappropriate. As a recent example, in work with Morada Nova ewes in a semiarid tropical region, Oliveira and Costa (2013) used models developed by da Silva et al. (2002) to calculate the heat loss by the respiratory system. They estimated that evaporative heat transfer ranged from 12 to $38 \mathrm{~W} \mathrm{~m}^{-2}$, while respiratory convection was insignificant, ranging from -0.002 to $0.004 \mathrm{~W} \mathrm{~m}^{-2}$. However, in the present study, we observed values of $0.65-8.94 \mathrm{~W} \mathrm{~m}^{-2}$ for evaporative heat loss and $0.74-1.59 \mathrm{~W} \mathrm{~m}^{-2}$ for respiratory convection. Therefore, these results confirm that the use of the same functions without considering the environment where animals were selected could cause large errors and the results would not represent the animal's thermal balance.

Differences between the tropical semiarid zone and temperate regions revolve around the challenge of maintaining animal homeothermy. The main contrast between tropical and temperate latitudes is the radiant environment (Da Silva et al. 2012). In tropical regions, the mean radiant temperature $\left(\mathrm{T}_{\mathrm{MR}}\right)$ is usually close to or higher than the air and body temperatures, so animals gain heat by thermal radiation. In contrast, heat loss by radiation almost invariably occurs in animals in temperate latitudes. In other words, genetic adaptation in the tropics gave rise to morphological and physiological characteristics that facilitate heat dissipation and protection from solar radiation (pigmented skin). By contrast, animals adapted to temperate regions have characteristics that help retain heat (great thermal insulation by the presence of 
wool). These statements are notable when we observe the animal body surface area and coat traits. Silanikove (2000) pointed out that the larger body surface areas of smaller races make them more efficient heat dissipaters in warm climates while a smaller body surface area may help to conserve heat in cold climates.

Coat surface characteristics can drive differences between individuals and determine the best avenue for heat dissipation under high temperature. The presence of long wool difficult the sensible (main surface convection) and latent heat loss from the skin surface. Several studies have shown that some long-wool sheep breeds selected for temperate zones, the respiratory system is the main avenue for heat transfer at high temperatures, but results are still conflicting (Cheviot and Scottish Blackface, Brockway et al., 1965; Merino, Hofmeyer et al. 1969; Dorset, Hofman and Riegle, 1977; Corriedale, Starling et al., 2002; Silva and Starling, 2003). Starling et al. (2002), working with Corriedale sheep in a tropical environment, reported that respiratory heat loss accounted for $70 \%$ of total heat loss, on average. Similar results were reported by Brockway et al. (1965) and Hofmeyer et al. (1969) in a study with Merino sheep. However, Silva and Starling (2003) described that the heat loss by the respiratory system represented $37 \%$ of total evaporation in Corriedale sheep. Despite these differences, it is clear that the respiratory tract plays a key role in thermal equilibrium of wool sheep selected for cold environments.

On the other hand, cutaneous evaporation seems to be the principal way to eliminate heat loss in animals raised on high ambient temperature as in tropical region. In study with Anglo Nubian goats acclimatized on tropical condition, Maia et al. (2016) described that under ambient temperature close to $30{ }^{\circ} \mathrm{C}$, thermal equilibrium was reached with $15 \mathrm{~W} \mathrm{~m}^{-2}$, $35 \mathrm{~W} \mathrm{~m}^{-2}$ and $40 \mathrm{~W} \mathrm{~m}^{-2}$ of respiratory evaporation, sensible heat loss (radiation and free convection), and cutaneous evaporation, respectively. Ligeiro et al. (2006) working with crossbred goats acclimatized to a tropical environment and purebred breeds adapted to temperate regions (Saanen and Alpine) observed similar results and greater cutaneous evaporation in crossbred animals. In addition, Maia et al. (2015) reported that under high ambient temperature $\left(36^{\circ} \mathrm{C}\right)$ cutaneous evaporation represented over the $93 \%$ of the total heat loss for "undefined breed goats" protected from direct and diffuse solar radiation in a semiarid tropical region.

According to our findings, the respiratory system is a significant avenue for latent heat loss under high temperatures, but no prior attempts had been made to identify what the main way for latent heat dissipation in wool-less sheep bred in tropical environment. Considering that the heat produced by metabolism in Morada Nova sheep can reach $45 \mathrm{~W} \mathrm{~m}^{-2}$ (Fonsêca, unpublished data) and heat loss (convection and evaporation) by respiratory tract of $9 \mathrm{~W} \mathrm{~m}^{-2}$ on average, the remaining $36 \mathrm{~W} \mathrm{~m}^{-2}$ should be lost in the animal surface by sensible way (radiation and convection) and cutaneous evaporation for the thermal equilibrium to be reached. In semiarid tropical environment, even in shade, during times of greatest thermal load, low thermal gradient (animal coat surface - ambient) and high radiant mean temperature can impair the elimination of heat by sensible avenues, and probably, sweat evaporation should assume this role. However, more studies are needed to investigate better this hypothesis because some part of the heat can be storage instead dissipated to the environment. The fact is that by the characteristics of the hair coat of Morada Nova sheep, the latent heat can be more easily dissipated at the skin than if it were covered by long wool.

\section{Conclusions}

Models presented here allow estimation of heat flow from the respiratory tract in Morada Nova sheep bred in a tropical region and use easily measured physiological and environmental parameters, such as the respiratory rate, ambient air temperature, and relative humidity.

Acknowledgments We gratefully acknowledge the support of the Animal Science Department and Animal Biometeorology Laboratory of the Universidade Estadual de São Paulo, Brazil. This study was supported by Research Foundation of São Paulo State (FAPESP; Process number: 2011/17388-6). We thank all members of the Behaviour and Biometeorology Group of the Universidade Federal da Paraíba (BIOET) and the members of the Animal Biometeorology Innovation Group of the Universidade Estadual de São Paulo (INOBIO).

\section{References}

Alexander G, Williams D (1962) Temperature regulation in the newborn lamb. VI. Heat exchanges in lambs in a hot environment 13:122143

Bennett JW (1973) Regional body surface area of sheep. J Agric Sci 81: $429-432$

Berman A (2005) Estimates of heat stress relief needs for Holstein dairy cows. J Anim Sci 83:1377-1384

Brockway JM, McDonald JD, Pullar JD (1965) Evaporative heat loss mechanisms in sheep. J Physiol Lond 179:554-568

Da Silva RG (2008) Biofísica ambiental: Os animais e seu ambiente. São Paulo, Brazil

Da Silva RG, Maia ASC (2011) Evaporative cooling and cutaneous surface temperature of Holstein cows in tropical conditions. Braz. J Anim Sci 40:1143-1147

Da Silva RG, Maia AS (2013) Principles of animal biometeorology. New York

Da Silva RG, Minomo FR (1995) Cicardian and seasonal variation of the body temperature of sheep in a tropical environment. Int $\mathrm{J}$ Biometeorol 39:69-73

Da Silva RG, Starling JMC (2003) Cutaneous and respiratory evaporation in sheep under high ambient temperatures. Braz. J Anim Sci 32: 1956-1961

Da Silva RG, La Scala N Jr, Lima Filho AE, Catharin MC (2002) Respiratory heat loss in the sheep: a comprehensive model. Int $\mathrm{J}$ Biometeorol 46:136-140 
Da Silva RG, Guilhermino MM, Morais DAEF (2010) Thermal radiation absorbed by dairy cows in pasture. Int J Biometeorol 54:5-11

Da Silva RG, Maia AS, Costa LLM, Queiroz JPAF (2012) Latent heat loss of dairy cows in an equatorial semi-arid environment. Int $\mathrm{J}$ Biometeorol 56:927-932

Egito AA, Mariante AS, Albuquerque MSM (2002) Brazilian program of animal genetic resources conservation. Arch Zootec 51:39-52

Fonsêca VFC, Saraiva EP, Pimenta Filho EC, Furtado DA, Mariz TAM, Silva ALS, Almeida MEV, Pinheiro AC (2014) Influence of the climatic environment and duration of labor on the motheroffspring interaction in Morada Nova Sheep. J Anim Sci 92:41234129

Gatenby RM (1986) Exponential relation between sweat rate and skin temperature in hot climates. J Agric Sci 106:175-183

Hofman WF, Riegle GD (1977) Thermo respiratory responses of shorn and unshorn sheep to mild heat stress. Resp Physiol $30: 327-338$

Hofmeyer HS, Guidry AJ, Waltz FA (1969) Effects of temperature and wool length on surface and respiratory evaporative losses of sheep. J Appl Physiol 26:517-523

Johnson KG (1991) Body temperatures and respiratory rates of freeranging Merino sheep in and out of shade during summer. Aust $\mathrm{J}$ Agric Res 42:1347-1357

Ligeiro EC, Campos Maia AS, daSilva RG, Loureiro CMB (2006) Heat loss by cutaneous evaporation associated with hair coat morphological characteristics of dairy goats bred in tropical environment. Braz J Anim Sci 35:544-549

Maia AS, da Silva RG, Loureiro CMB (2005) Respiratory heat loss of Holstein cows in a tropical environment. Int J Biometeorol 49:332 336
Maia ASC, da Silva RG, Nascimento ST, Nascimento CCN, Pedroza HP, Domingos HGT (2015) Thermoregulatory responses of goats in hot environments. Int J Biometeorol 59:1025-1033

Maia ASC, Nascimento ST, Nascimento CCN, Gebremedhin KG (2016) Thermal equilibrium of goats. J Therm Biol 58:43-49

Mitchell B (1972) Relationship between body weight and tidal volume during general anaesthesia in sheep, cattle, pigs and horses. Vet Anaest Analg 3:56-60

Neiva JNM, Teixeira M, Turco SHN, Oliveira SMP, Moura AAAN (2004) Effect of thermal stress on the physiological and performance parameters of sheep maintained in confinement in the northeast of Brazil. Braz J Anim Sci 33:668-678.

Oliveira SEO, Costa CCM (2013) Respiratory heat loss in Morada Nova sheep in Brazilian semi-arid regions. J Anim Behav Biometeorolol $1: 17-20$

Schmidt-Nielsen K (1991) Animal physiology: adaptation and environment, 4th edn. Cambridge University Press, Cambridge

Silanikove N (2000) The physiological basis of adaptation in goats to harsh environments. Sma Rum Res 35:181-193

Silva RB (2013) Effect of environment in the physiological variables and methane emission associated to production and heat loss in sheep. Dissertation, Universidade Estadual Paulista

Starling JMC, daSilva RG, Cerón-Munhoz M, Barbosa GSSC, Paranhos da Costa MJR (2002) Analyses of some physiological variables for evaluation of adaptation level on sheep submitted to heat stress. Braz J Anim Sci 31:2070-2077

Stevens DG (1981) A model of respiratory vapor loss in Holstein dairy cattle. Trans ASAE 24:151-158 